\title{
La propiedad de la tierra y el agua en el Noroeste Argentino. El caso de los campos comuneros en el valle de Hualfín
}

Bernarda Zubrzycki, ${ }^{1}$ Marta M. MafFia ${ }^{2}$ y Leonardo Pastorino ${ }^{3}$

\section{RESUMEN}

Los habitantes de Asampay (Catamarca, Argentina) han adoptado un sistema de usos y costumbres conformado por normas comunitarias que delinean el aprovechamiento de los recursos naturales escasos de la región, específicamente la tierra y el agua. Dicho sistema ofrece la particularidad de mostrar un proceso de adaptación al medio, reflejado en la elaboración sistemática de reglas de convivencia-desarrollado con anterioridad a la sanción del Código Civil en 1871- el que se sostuvo hasta nuestros días, como un camino paralelo y alternativo al modelo individualista que inspira nuestra legislación. En este trabajo analizamos la concepción que los lugareños de Asampay tienen sobre la propiedad de la tierra, en relación a la situación que presentan otras poblaciones de la región andina y a la normativa jurídica vigente en Argentina.

Palabras claves: propiedad de la tierra - reglas comunitarias - valle de Hualfín.

\section{ABSTRACT}

The people of Asampay (Catamarca, Argentina) have developed a community normative system that regulates the access to scarce land and water. This system gives the opportunity of observing a process of environmental adaptation, as reflected in its systematic elaboration of rules for coexistence. Developed prior to the sanction of the Civil Code in 1871, it is, to this day, considered to be different from the individualistic model that inspires our civil legislation. In the current stage of our research, we have aimed to analyze the proprietorial notions Asampay natives have about land, in relation to that of other villages in the Andean region and in comparison to Argentina's legal system.

Key words: land tenure and property - community rules Hualfin valley.

Recibido: septiembre 2003. Manuscrito revisado aceptado: febrero 2004.

1 Departamento Científico de Etnografía, Facultad de Ciencias Naturales y Museo, Universidad Nacional de La Plata. Paseo del Bosque s/nº, La Plata (1900), Buenos Aires. Email: berzub@aol.com

2 Departamento Científico de Etnografía, Facultad de Ciencias Naturales y Museo, Universidad Nacional de La Plata. Investigadora CONICET. Paseo del Bosque s/n $\mathrm{n}^{\circ}$, La Plata (1900), Buenos Aires. Email: migraciones@uolsinectis.com.ar

\section{Introducción ${ }^{4}$}

Este trabajo forma parte de una investigación más amplia que realizamos en equipo, junto a arqueólogos, antropólogos, biólogos y especialistas en derecho agrario, en Asampay, provincia de Catamarca, Argentina. El principal objetivo que nos planteamos, fue analizar la concepción que los lugareños de Asampay tienen sobre la propiedad de la tierra, en relación a la situación que presentan otras poblaciones de la región andina y a la normativa jurídica vigente en Argentina (Figura 1).

El departamento de Belén, al que pertenece la localidad de Asampay, está situado en el oeste de la provincia de Catamarca. Orográficamente está representado por formaciones montañosas, que poseen una dirección general norte-sur con alturas que sobrepasan los 3.000 m.snm. La principal cuenca de drenaje del departamento es la del río Hualfín-Belén, de la que dependen, de norte a sur, numerosas poblaciones: Hualfín, San Fernando, La Ciénaga, La Puerta de San José, y Belén, entre otras, las cuales hacen uso de estas aguas para sus actividades agrícolas tradicionales (tanto en tecnología como en los tipos de cultivos). En la región, alrededor del $66 \%$ de las explotaciones agroganaderas son de propiedad personal y cerca del $9 \%$ son de propiedad familiar. Hay más de un millar de explotaciones que no poseen límites definidos, constituyendo alrededor del $20 \%$ del total. Las actividades productivas se basan en tres tipos de cultivos: industriales, frutales y hortalizas. La vid es el único cultivo industrial en la actualidad; entre los frutales se destacan el nogal, el olivo y el duraznero; y entre las hortalizas, la más importante es la papa. Sobre la cuenca del

3 Facultad de Ciencias Naturales y Museo, Universidad Nacional de La Plata, Paseo del Bosque S/N (1900), La Plata, Buenos Aires. Email: pastorinoleonardo@yahoo.com.ar

4 Una versión del presente trabajo ha sido presentada en el XXV Convegno Internazionale di Americanistica (Peruggia, Italia) en mayo de 2003. 


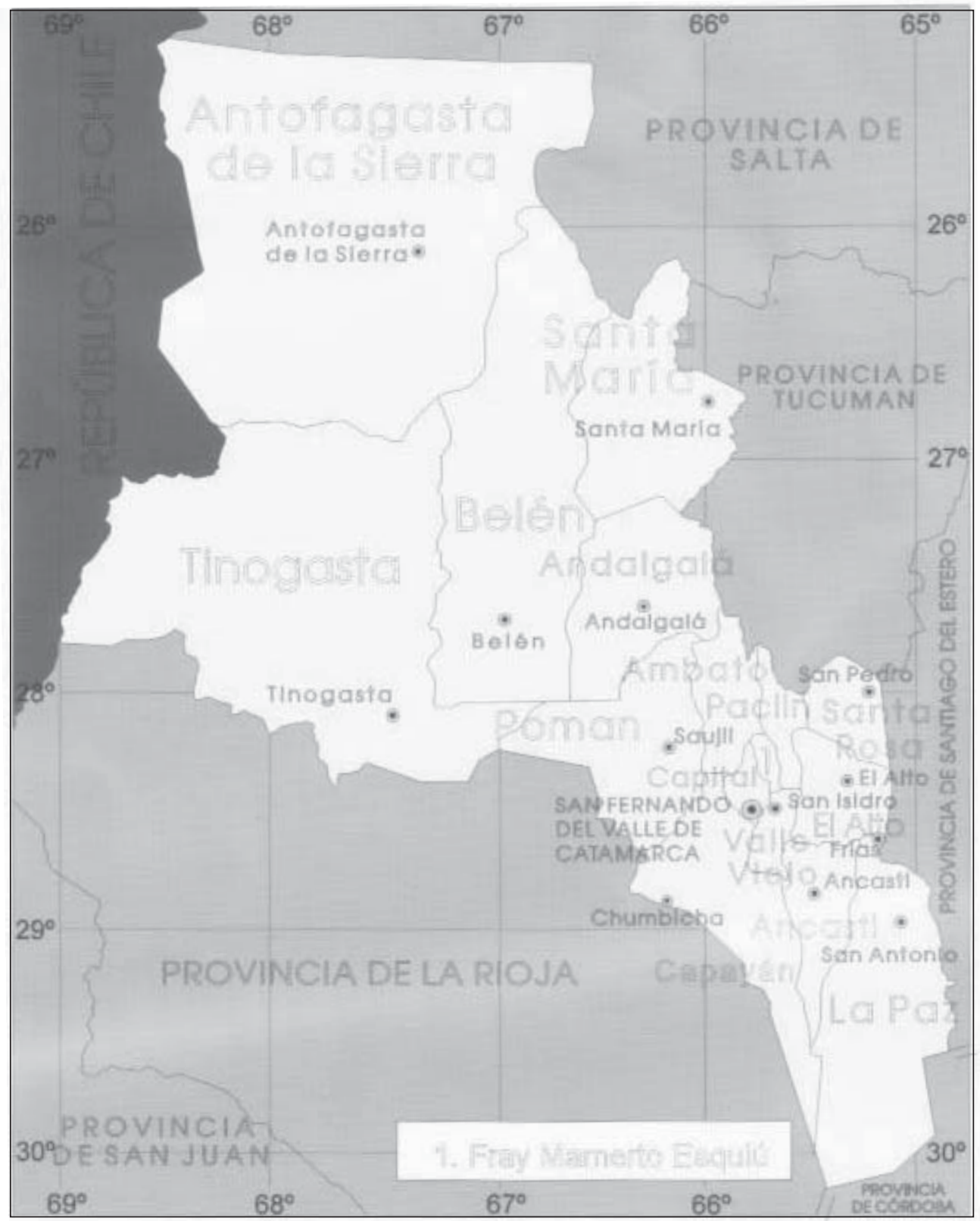

Figura 1. Mapa de la Provincia de Catamarca (Argentina).

río Belén se cultivan extensiones importantes de especies aromáticas para condimentos.

La actividad ganadera principal es la cría de camélidos autóctonos (99.9\% del total provincial), y en segundo lugar, está la cría de ovinos $(81 \%$ del total provincial). Ambas actividades se producen principalmente en la puna. En cambio, en las zonas llanas se realiza la cría caprina $(48 \%$ del total provincial), y bovina.
La actividad agroindustrial está representada por el procesamiento de aceitunas, la conserva de hortalizas, dulces regionales, molinos pimenteros y bodegas. Dentro de estas industrias artesanales se producen tejidos en lanas de oveja, llama, guanaco, y antiguamente, de alpaca y vicuña. Belén fue uno de los centros más importantes donde se habría de desarrollar la industria textil a ritmo acelerado, basada en forma predominante, casi exclusiva, en la mano de obra femenina 
La localidad de Asampay (1.800 m.snm) se encuentra ubicada al pie de los cerros que limitan por el occidente al valle de Hualfín. Actualmente la actividad agroganadera está restringida a ganado menor (cabras y ovejas), burros, mulas y escasos equinos; los cultivos para la venta, a la nuez y eventualmente el durazno y el comino; y para el consumo familiar, el maíz, el zapallo, la cebolla y la uva. El tejido en telar continúa siendo la actividad principal de la población femenina, aun cuando su producción se ha reducido considerablemente, situación que contribuye a la salida de las jóvenes a trabajar fuera de la unidad doméstica. Respecto a los hombres, aquellos que no migran y están en la categoría de inactivos como jubilados y pensionados, complementan sus ingresos con el producto de las actividades agrícolas para el autoconsumo. El resto combina labores rurales y urbanas, por ejemplo, las cosechas estacionales, trabajos temporales en el rubro de la construcción y empleos estatales (Maffia y Zubrzycki 2001).

Los habitantes de Asampay han adoptado un sistema de usos y costumbres conformado por normas comunitarias que delinean el aprovechamiento de los recursos naturales de la región, particularmente la tierra y el agua. El mencionado sistema ofrece la particularidad de mostrar un proceso de adaptación al medio, reflejado en la elaboración sistemática de reglas de convivencia -que tiene su origen antes de la sanción del Código Civil en 1871- el que se sostuvo, hasta nuestros días, como un camino paralelo y alternativo al modelo individualista que inspira nuestra legislación.

Lo que hoy llamamos Catamarca, junto a otras provincias del Noroeste Argentino (Jujuy, Salta y Tucumán) constituían la provincia más meridional del imperio incaico: el collasuyo. Si bien, por lo investigado hasta el momento, las poblaciones de los campos comuneros estudiados no derivarían de grupos y asentamientos indígenas ¿podemos determinar de manera definitiva la ausencia de usos y costumbres respecto a la propiedad de la tierra propios de las sociedades andinas?

En la localidad de Asampay se han encontrado evidencias arqueológicas de ocupaciones pertenecientes al Período Formativo Temprano y Medio (González 1955) consistentes en fondos de vivienda correspondientes a la Cultura Condorhuasi en su Fase río Diablo (González y Cowgill 1975), también enterratorios de la Cultura Ciénaga, y un asentamiento rural del momento de contacto Ciénaga-Aguada en el sitio Barrealito de Asampay.

La Cultura Belén (González 1955) se desarrolló durante el Período de Desarrollos Regionales (1100-1480 DC) del Noroeste Argentino, en los departamentos de Belén y Tinogasta de la provincia de Catamarca. En su organización sociopolítica pudo ser un Señorío o Cacicazgo con una jerarquización en los poblados. Tuvo su territorio nuclear en el valle de Hualfín, y desde allí se expandió hacia los valles aledaños y al ambiente puneño más alto. Dentro de su territorio nuclear la complejidad social y la jerarquización son evidentes en las grandes obras agrícolas y en las diferencias entre sitios habitacionales.

Durante el Período de Influencia Incaica (14801535 DC) estas jefaturas fuertes fueron subyugadas por la conquista incaica, que significó, por su impacto, un gran cambio en las culturas regionales. La posterior conquista española y los cambios sociopolíticos marcaron el definitivo derrumbe de las modalidades autóctonas y la introducción del modo de vida español que fue rápidamente asimilado por los grupos indígenas. Hacia el siglo XVIII, la población es predominantemente española o españolizada.

Los campos comuneros tienen su antecedente en las mercedes de tierra otorgadas por la corona española durante la época colonial ${ }^{5}$; a través del tiempo se fueron vendiendo, heredando y donando derechos y acciones de uso sobre los mismos, dando lugar a una compleja situación jurídica respecto a la propiedad. Como, por otra parte, no se tramitaban los juicios sucesorios durante generaciones, no se podía saber a cuánto alcanzaba el derecho de cada uno, ni cuántos eran exactamente los herederos y los concesionarios (CFI 1964). Aún hoy, ningún habitante de la población analizada ha iniciado juicios sucesorios, deslindes o mensuras para prescripciones adquisitivas, legitimando en muchos casos su derecho a la tierra a través del parentesco con los primeros propietarios.

\footnotetext{
Estas mercedes eran el medio por el cual la Corona premiaba a los súbditos que participaban en la conquista de territorios (la institución ya existía en el Derecho Castellano y fue luego trasplantada a América); el dominio de las tierras descubiertas correspondía al Rey, la gracia o merced real era el título jurídico para que los particulares accedieran al dominio privado de la tierra.
} 
Al inicio de la investigación nos preguntamos si ¿el nombre "campos comuneros" hace referencia al uso comunitario de los mismos?, ¿es propiedad común de un grupo de vecinos y/o parientes, o hay acceso libre a los campos?, ¿existe la comunidad como forma de organización sociopolítica y económica?

Ante todo, es necesario distinguir los conceptos de "propiedad común" y "acceso libre", ya que con frecuencia se encuentra en la literatura sobre el tema el uso confuso de ambos términos, o bien, se cae en la contradicción de describir los recursos no poseídos por nadie como propiedad común (Sánchez López 1998).

El autor mencionado, analizando los modelos de gestión de los recursos comunales en Castilla y León (España), considera que el acceso libre a los recursos naturales es un régimen de aprovechamiento que no debe ser incluido en el régimen de propiedad común. Cuando se habla de acceso libre a los recursos se excluye implícitamente que éstos sean propiedad de alguien (individual o colectiva), porque la propiedad excluye formalmente la disponibilidad general o universal de los bienes.

La propiedad común no es propiedad de cualquiera, el término implica que los usuarios potenciales del recurso que no son miembros de un grupo de propietarios, son excluidos. La propiedad común es una distribución de los derechos de propiedad sobre los recursos en la que un número de propietarios son coiguales en su capacidad jurídica de usar el recurso.

\section{Uso y tenencia de la tierra en la región andina}

Isla (1992) trabajó con localidades aymara del altiplano boliviano (provincia de Ingavi, departamento de La Paz) en las riberas del lago Titicaca, definiendo a la comunidad como modo de producción y distribución, forma de organización social, política y económica. Según este autor, las específicas formas de solidaridad que se dan en el mundo aymara, la resolución entre lo individual y lo colectivo, los vínculos intraétnicos fuertemente contrapuestos a los externos, la apropiación del territorio (la geografía, pero también el territorio simbólico) constituyen la forma comunidad. Es un conjunto de respuestas políticas y culturales, que constituyen el modo de produc- ción y reproducción de lo social (Isla 1992: 172). Propone cinco principios que alcanzan para definir de manera abstracta un modo de producción, distribución y consumo, próximo al funcionamiento real de la economía de las comunidades del altiplano norte de Bolivia:

1) Control comunal del medio de producción estratégico: la tierra.

2) Maximización de las actividades productivas.

3) Control de la diferenciación interna.

4) Doble racionalidad simultánea.

5) La búsqueda del excedente por cada unidad doméstica.

Específicamente nos interesa el primer punto. En las comunidades que bordean el lago Titicaca se dan tres tipos tradicionales de tenencia de la tierra: sayana, aynuca y de pastura, a los que se agregan otros dos, producto de la Reforma Agraria de 1953: privadas y de cooperativa. La sayana es la parcela de una familia donde se practica agricultura intensiva. Es, además, la base de su identidad étnica ya que la relación del hombre con su parcela implica la construcción cultural de "personas", y permite entender la unión entre el hombre aymara y su tierra, su comunidad a través de su parcela. Para acceder a una sayana el "originario" o miembro nacido en la comunidad, debe madurar, lo que implica asumir diferentes responsabilidades individuales y sociales (Isla 1992: 178).

Las tierras de cultivo conviene tenerlas divididas para acceder a varios microambientes. Sólo se logra esto por herencia o mediante el matrimonio entre cónyuges de diferentes zonas de la misma comunidad.

El convertirse en "persona" también le permite a un aymara acceder a otro tipo de tierras: las llamadas aynucas, "del común", "de comunidad" o "de reparto", controladas por la Asamblea, y que son repartidas y rotadas en cada ciclo productivo. La Asamblea es una institución política con carácter deliberativo-ejecutivo legitimada por la ley consuetudinaria aymara y presente en la mayoría de las comunidades de los Andes peruanos y bolivianos.

Las tierras de pastoreo están por encima de los $4.200 \mathrm{~m}$.snm dentro de los límites de la comuni- 
dad, donde las pasturas naturales pueden soportar el ganado durante casi todo el año.

La propiedad privada de la tierra hace referencia a tierras tituladas e inscritas en el registro de propiedad, aunque son pocos los que pagan impuestos. Esta tendencia comenzó con la reforma agraria, pero aún no es predominante.

La cooperativa analizada por el autor era llevada adelante por un grupo de parentesco de la misma comunidad, cultivando productos para el mercado. Los 56 socios aportan el 55\% de las tierras cultivables de la comunidad y una comisión interna controla las jornadas de trabajo y el reparto del producto de la cosecha. A pesar de ser la cooperativa una forma de producción y distribución ajena al mundo aymara, ha sido resignificada y combinada con el sistema tradicional de producción y acceso a la tierra (Isla 1992: 184).

Otra situación es la analizada por Calvo y Regalsky (1994) también para Bolivia, pero esta vez en la provincia de Mizque, departamento de Cochabamba. Se trata de la población de origen quechua de Raqaypampa. A fines del siglo XVI se instalaron en la zona las primeras haciendas coloniales, constituyendo la modalidad de explotación agrícola dominante en la región, como en casi toda el área andina boliviana hasta la reforma agraria. Los hacendados propietarios de la tierra recibían, en calidad de renta por un pedazo de terreno usufructuado, trabajo gratuito y otros bienes y servicios de las familias que allí habitaban. En Mizque, las comunidades indígenas originarias aparentemente no sobrevivieron al siglo XVII, caso contrario al de las regiones vinculadas al altiplano aymara. Luego de la reforma agraria los hacendados fueron expulsados y los terrenos de las haciendas pasaron a manos de los ex peones organizados en sindicatos agrarios. Por lo general, estos sindicatos se organizaron en base al territorio y la población que formaba parte de la ex hacienda. La adjudicación de terrenos realizada con la reforma legalizó la propiedad de cada familia sobre las parcelas que ya usufructuaba durante la hacienda y remitió a control comunal los montes y las tierras arrebatadas a los hacendados.

En las alturas, las tierras de cultivo y de pastoreo son de propiedad familiar; en los montes el sindicato adjudica la tierra de cultivo a cada agricultor, mientras que las tierras de pastoreo y recolec- ción son usufructuadas por los comuneros de acuerdo a las costumbres. El derecho comunal restringe la libre disponibilidad de las tierras familiares e impide su enajenación a forasteros. En la actualidad el principal medio de acceso a la tierra es la herencia, ya que no queda más tierra libre para repartir.

Un ejemplo sobre la propiedad de la tierra para Perú es el analizado por Ossio Acuña (1992). El autor estudia la comunidad de Andamarca, en la provincia de Lucanas, departamento de Ayacucho. El primer requisito para acceder a los bienes de la comunidad es ser andamarquino. Este estatus se adquiere bien por haber nacido en la localidad, de padres andamarquinos que se han casado legalmente, o por contraer matrimonio con una persona oriunda del lugar y cumplir con las obligaciones públicas.

La comunidad encierra una gran variedad de formas de propiedad. Su peculiaridad es que estas oscilan entre un extremo colectivo y otro individual. La propiedad colectiva está dada sobre los pastos de la puna o moyas, los aypo, el yayanchiccata y la Cofradía de la Santísima Trinidad, los que a continuación se describen:

Las moyas son de dominio público. Esto es imperativo ya que los pastos no son cultivados y se agotan rápidamente. En la esfera de la propiedad agrícola el equivalente más cercano a estos pastos comunales de la puna es el aypo. Consiste en un amplio sector de terrenos de secano destinado al cultivo de papas que, dividiéndose en parcelas, es redistribuido anualmente entre los comuneros. El yayanchiccata era un terreno cultivado con maíz y que estaba bajo la advocación del patrón del pueblo, el Espíritu Santo, y era trabajado por los mayordomos de la iglesia matriz. Su cultivo dejó de practicarse por la década de 1960 . La Cofradía de la Santísima Trinidad es un sector de la puna que está reservado exclusivamente para el pastoreo de vacunos pertenecientes a cuatro de los veinte santos venerados en la iglesia matriz de Andamarca. El destino del ganado es por lo general proveer de apoyo económico a la iglesia.

Las parcelas de cultivo de maíz son de propiedad individual. Lo que la diferencia de otros tipos de propiedad es el tiempo de usufructo; en este caso es por toda la vida además de poder ser vendido a 
otro comunero o transmitido en herencia. Sin embargo, es la comunidad la que cede derechos sobre la propiedad, pudiendo en todo caso los propietarios ceder sus derechos a terceros. La posesión de la tierra comienza a partir del matrimonio por compraventa, herencia o donación.

Finalmente, entre el extremo colectivo y el individual existe la propiedad familiar. Se trata de las yapanchicpa, que comúnmente son cercos de papas en terrenos de secano, poseídos en común por una familia extensa. También de propiedad familiar son las lucri chacra, parcelas con maíz cultivadas en común por todos los miembros del grupo familiar.

\section{La propiedad comunal en Argentina}

En el derecho argentino no existe la propiedad comunal. El Código Civil sólo concibe la propiedad privada - de personas físicas o jurídicas, pudiendo ser estas sólo las reconocidas por el ordenamiento: sociedades, asociaciones o fundaciones e Iglesia- o las tierras fiscales que pueden ser del Estado Federal, de las provincias o de los municipios pero que pertenecen o se gestionan en sus dos diversos regímenes jurídicos -dominio público o dominio privado del Estado- por el propio Estado titular.

Luego de un extenso período sin otros modelos posibles, recién la Constitución Nacional argentina, reformada en 1994, reconoce la preexistencia étnica y cultural de los pueblos indígenas, la personería jurídica de sus comunidades (conforme a sus propios modos organizacionales, es decir, sin imponer el régimen de personería jurídica de las leyes civiles) y la posesión y propiedad comunitaria de las tierras que tradicionalmente ocupan.

Por la Ley 23.302 de 1985, este reconocimiento debe provenir del hecho de descender de poblaciones que habitaban el territorio en la época de la conquista (criterio étnico), mientras que por la Ley 24.071 de 1992, que adopta el Convenio 169 de la OIT sobre pueblos indígenas y tribales en países independientes, se agrega el tema de la conciencia (concepto cultural y volitivo).

Las relaciones colectivas son eje de la organización indígena. Por eso se reconoce la propiedad o tenencia de la tierra al conjunto y no a los indivi- duos particulares; se le otorga personería jurídica, se mantiene esa entidad preservándola en la tenencia de la tierra y se protege esa conservación impidiendo que la misma sea objeto de enajenación, embargo o fraude. También se preservan las industrias o actividades comunitarias y los valores, instituciones y prácticas de esas comunidades.

Madrazo (1970) haciendo un estudio histórico de la tenencia colectiva de tierras en la provincia de Jujuy, concluye que durante la época colonial se mantuvo vigente en gran medida la tenencia indígena comunal, organizada y reglamentada bajo el régimen legal establecido por la corona española; la Recopilación de Leyes de los Reinos de Indias documenta perfectamente el propósito de la corona de proteger la propiedad indígena.

El proceso de desintegración se precipitó después de la independencia. En el siglo XIX, una vez iniciada la vida nacional, finalizó con el cese de la legislación española, la protección legal organizada de la tenencia indígena. Se produjo el ocaso definitivo de la tenencia comunal que sólo aparece en forma esporádica en las regiones más apartadas.

Isla (1992) analiza algunas comunidades de Jujuy, en el departamento de Yavi, encontrando "ecos de la forma comunidad", algunos poblados mantienen tierras para pastoreo en común, no subdivididas por "voluntad de la comunidad". En otros casos, como por ejemplo Suripugio, al noreste del mencionado departamento, los pobladores reclaman que les sea reconocido el derecho comunal sobre las tierras del caserío y han solicitado su entrega "en comunidad".

Hocsman $(1999,2000)$ estudia una comunidad aborigen en el departamento de Iruya, Salta, donde el espacio agrario pastoril es usado en forma comunal y las "chacras" apropiadas individualmente, como área de cultivos familiares. Hoy las tierras de la localidad pertenecen por ley a sus pobladores, en forma comunitaria, aunque aún no se han entregado los títulos de propiedad. Cada familia posee tierras que provienen de herencias, y estas tenencias son reguladas por una Comisión Vecinal con personería jurídica.

En Tucumán, la comunidad de Amaicha del Valle (Isla 2002) tiene su origen en la adjudicación de tierras otorgada por cédula real en 1716 a las tri- 
bus indígenas quilmes. En la actualidad se otorga la filiación comunal tanto por vía masculina como femenina, y no es necesario haber nacido allí para ser reconocido como comunero, es decir, la filiación no está ligada al nacimiento en el territorio de la comunidad, sino a la línea de ascendencia paterna o materna. Si alguno de los padres es comunero, los hijos lo serán y pueden reclamar sus derechos.

Los tipos jurídicos de posesión y tenencia de la tierra en Amaicha son varios: propiedad privada (superficie de tierra con título inscrito en el Registro General de la Propiedad o en proceso de inscripción, o boleto de compraventa. También se incluye aquí a quienes pagan sus impuestos en la oficina de la Comuna Rural. Esta tierra puede venderse, arrendarse, alquilarse); propiedad autorizada por la comunidad (aquellas superficies cedidas por las autoridades de la comunidad a comuneros siguiendo el derecho consuetudinario).

En síntesis, en contraste con las vastas regiones de los Andes bolivianos y peruanos donde persiste la forma comunidad y la tenencia comunal de la tierra, en el Noroeste Argentino predomina el pequeño productor parcelario con propiedad individual sobre la tierra de cultivo, donde por lo general sólo se utiliza en común las tierras para pastoreo. Sin embargo, el derecho a la propiedad comunal ha comenzado a ser reclamado por varios grupos indígenas organizados en asociaciones civiles, donde la "comunidad" se encarga de distribuir las parcelas de tierras entre sus miembros.

\section{El campo comunero Asampay}

Como mencionamos en la introducción, los campos comuneros tendrían su origen en las mercedes de tierra dadas por la Corona española.

El pedido de tierras por parte de los conquistadores sirve como hito demarcatorio del final del Período Hispano-Indígena en el Noroeste Argentino (Sempé 1976); existen fechas seguras que marcan la definitiva desaparición de los indígenas como grupos culturales coherentes en la zona estudiada: según Larrouy:

"es de notar que ya en 1688 no quedaba ningún pueblo de indios en el departamento (Belén). En éste, pues, todas las poblaciones derivan de es- tancias $^{6}$ de españoles; pero no conozco los orígenes de ninguna de las que están situadas al norte de La Puerta de San José" (1921: 25).

En 1678 el presbítero Bartolomé de Olmos y Aguilera, cura y vicario de San Juan de la Ribera de Londres, solicita al gobernador de Tucumán una merced de tierras en el valle de Famayfil (hoy Belén). Allí fundó el Santuario de Nuestra Virgen de Belén en 1681 y organizó el primer poblado.

La nueva población rápidamente prosperó especialmente gracias al comercio de ganado que las provincias del sur (La Rioja, San Juan y Mendoza) tenían con el Alto Perú; los conductores de tropas cruzaban por la misma plaza de Belén. Un documento fechado en 1772 y redactado por los vecinos señala que:

“al norte están las estancias y potreros de Belén (...) donde se crían y mantienen crías de animales, vacas, caballos, mulas, y se invernan cantidades anualmente, aún del Valle (de Catamarca) y Rioja y Córdoba y esta su jurisdicción" (Archivo Provincial de Catamarca, Caja 4, Leg. 6).

Algunas de estas estancias eran la de San Fernando y Hualfín.

Todavía en la segunda mitad del siglo XIX la actividad ganadera era importante:

“...bueyes y obejas se importan a Chile, después de invernadas en los alfalfares del mismo departamento (Belén). Mulas i burros a Bolivia i Perú (...) los cueros se llevan a Tucumán, de donde se traen suelas i calzados" (Espeche 1875: 346).

Respecto a Asampay, sus primeros pobladores, según los datos relevados hasta el presente, se establecieron a fines del siglo XIX; hasta ese momento no había habido una ocupación efectiva por parte de los "derechosos" , es decir, se utilizaba el campo para pastoreo pero no se habitaba de forma permanente en él.

6 En algunos de los documentos analizados, así como en el padrón del catastro realizado en 1981 se menciona la Estancia Asampay. Larrouy (1921: 15) señala que el término "estancia" era usado en la época colonial para referirse a una merced que se ha poblado.

7 El término se refiere a herederos o cesionarios de derechos hereditarios en una merced o campo comunero (CFI 1964). 
Las primeras familias fueron puesteros emigrados desde Tinogasta (departamento catamarqueño al oeste de Belén), El Tolar (población ubicada a unos $4.000 \mathrm{~m} . \mathrm{snm}$ a la cual se llega a lomo de burro desde Asampay), La Ciénaga, San Fernando, Hualfín y otras zonas del departamento de Belén, que trabajaban los "rastrojos" (parcelas cultivadas) y cuidaban la "hacienda" (majadas de cabras y ovejas), son algunos de estos puesteros quienes comprarán derechos sobre las tierras en las que ya vivían.

"Mis padres eran de Tinogasta, después estaban en El Tolar trabajando, ellos quisieron venir porque allí no tenían propiedades, derechos de campo ni a donde vivir. Toda la gente de ahí eran criadores, andaban por la cordillera hasta Chile. Mi padre trabajaba de peón, se iba a buscar la vida (...). Trabajaba en El Tolar y luego bajó hasta El Chorro [puesto en la sierra al pie de la cual se encuentra Asampay] y trabajaba como mediero de Marcelino Ochoa, que vivía en El Tolar (...) Ahí en El Chorro nací yo en 1919. Tenían hacienda y la llevaban por distintos puestos en los cerros y después le compró un derecho de campo con ocho horas de agua a Ochoa y se asentó en Asampay". ${ }^{8}$

El pastoreo de ganado exigía la ocupación total del campo, pero como no podía dividírselo -los alambrados y otros medios, como cercos, pircas y tapiales resultaban carísimos en extensiones tan grandes- los sucesores de los primitivos dueños lo mantenían indiviso, usándolo en conjunto (CFI 1964). Cada familia tenía su ganado "marcado", algunas incluso llegando a registrar formalmente su marca en Belén, lo que permitía separarlo cuando era preciso.

Si bien no había un pastoralismo transhumante en el sentido de la utilización de ambientes situados a diferentes alturas según sea verano o invierno con las consecuentes migraciones desde el piedemonte a la montaña, es decir, un comportamiento seminómade por parte de los pastores y su familia (Bocco de Abeyá 1988), la "hacienda" se llevaba por diferentes puestos, entre el campo y el cerro por los alrededores del caserío, y se usaban pequeños arroyos y aguadas también en forma común.

8 Todos los fragmentos de entrevistas citados en el presente artículo fueron registrados en trabajos de campo realizados entre 1995 y 2002 en Asampay.
Un documento que nos brinda información respecto a la actividad ganadera de la población es el diario del Ingeniero Weiser (1926 Ms: 35)9

"es muy limitada la población de la quebrada Asampay, apenas cuatro casitas con sus correspondientes chacras y fincas. La riqueza de los habitantes la forman las grandes majadas de cabras y ovejas que encuentran un pasto bueno y fuerte en los cerros bien húmedos por las frecuentes lluvias del verano y las garúas de la primavera y otoño

"Antes tenían cada uno su hacienda, estábamos todos a cuidarla. Por ejemplo iba yo de acá, mi sobrino de arriba, todos los vecinos salíamos cinco o seis al cerro. Cada uno tenía su grupo de hacienda y por lo menos la carne no la necesitábamos comprar".

"Antes teníamos muchas cabritas, antes el cuero se vendía mucho, ahora ya ni pregunte, nada. Los compraban todos los comerciantes grandes, venían de La Ciénaga, de Buenos Aires. Ahora que las vamos a vender si ya nada más las tenemos para adorno, porque yo no las quiero acabar nomás, no, si son muy poquitas".

"Mis hermanos grandes, mis abuelos, mi mamá, ellos no tenían ningún trabajo de empleo ¿no?, pero en la casa se hacía de todo, tenían la hacienda, ella ponía de todo, tejido... con todo se vendía. Como digo, el cuero de cabra valía mucho, con eso nos compraba la mantención. Ahora casi nadie quiere irse al cerro, porque ya no quieren... ya no tienen casi animales, en cambio antes se usaba mucho, porque antes había mucha hacienda. Ahora ya el que tiene, tiene poquito".

"Mi abuelo vivió aquí ... pero no era como ahora. No, la gente dice que era mejor entonces... porque antes había mucha hacienda, no se sufría de las cabras, tenían todos más. Cuantas cabras solía tener mi papá, esa loma solía estar cubierta, en esas lomaditas se veían sólo cabras, cualquier cantidad de cabras. Y después ha entrado la plaga del león".

9 Diarios realizados durante las expediciones arqueológicas al Noroeste Argentino entre 1920 y 1926 y que se hallan en el Departamento Científico de Arqueología del Museo de La Plata. 


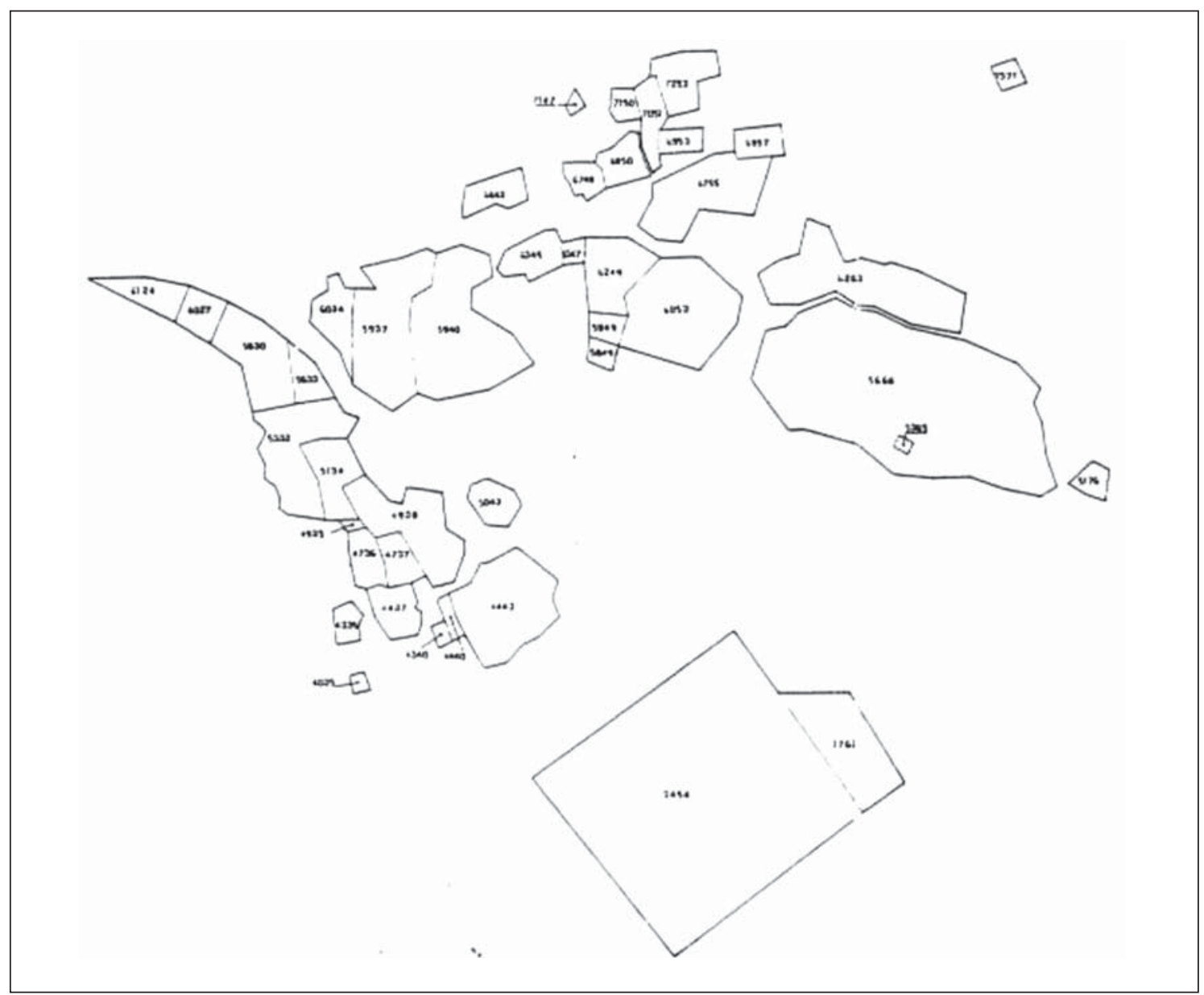

Figura 2. Mapa catastral de Asampay (Catamarca).

Actualmente las familias tienen cercadas las parcelas ${ }^{10}$ donde están las casas y los rastrojos, las que consideran de propiedad privada y que fueron registradas en el relevamiento realizado por la Dirección Provincial de Catastro en 1981 (Figura 2), pero también se reconocen como propietarios del campo, "monte" o "campo blanco" donde pastan los animales y se recoge leña. El uso de estos campos es en común ya que nadie puede establecer exactamente qué porción del mismo le corresponde, no porque sean tierras de la comunidad o de los vecinos del pueblo, sino porque nunca se dividió la propiedad común a través del sistema de sucesión.

10 El $72.5 \%$ de los predios tiene una superficie menor a una hectárea, el $22.5 \%$ entre una y cinco hectáreas y sólo el 5\% de los predios supera las cinco hectáreas.
Esta situación se resolvía insuficientemente con el traspaso de los derechos correspondientes a una parte "ideal" sobre la herencia, imposible de ser reconvenida en la adjudicación de una parcela "real" sin el juicio sucesorio. Parcela que, de procederse en el modo estipulado por la ley civil, podría convertirse en improductiva.

El primer antecedente ${ }^{11}$ de compra y venta de derechos que hemos registrado para el campo comunero Asampay es una venta realizada en 1860 de “... un derecho de potrero en común sito en el

11 El análisis de los antecedentes, propietarios y límites del campo se realizó en base a Escrituras del Juzgado de Paz de Belén depositadas en el Archivo Histórico de Catamarca, e hijuelas -documentos que se dan a cada uno de los herederos y en los que constan los bienes que les tocan en la partición- suministradas por los pobladores de Asampay. 
lugar de Asampay". Para principios del siglo XX encontramos, por ejemplo, la venta de "... un derecho común en el campo y cerro de Asampay, equivalente a tres octavas partes de la mitad de la citada estancia o campo común". Así como también "... una finca con viña y otros árboles de castilla, terrenos de sembradíos y potreros alfalfados", o:

“... una acción y derecho en la estancia común e indivisa denominada Asampay (...) incluyendo la misma un rancho, una quinta, terrenos de sembradio, derecho de pastoreo y derecho de cuatro días de agua en turno de cada diez y seis días".

Los límites del campo o estancia Asampay mencionados en los documentos son generalmente accidentes geográficos poco definidos o propiedades de otros habitantes de la zona; por ejemplo, en una escritura de venta de un derecho común en el campo de Asampay se lo ubica

“... poco más o menos dentro de los siguientes linderos: al norte la Estancia del Carrizal, por el este con terreno de Palo Blanco y sucesión de Don Belisario Sosa, por el sud con Río de Chicho, o sea Las Mansas y Quebrada Grande o sea Guasayaco y por el oeste con cima del cerro".

En otra venta se menciona

“... la estancia común e indivisa Asampay ubicada en el distrito La Ciénaga de este departamento, siendo la extensión aproximada de la estancia de cien kilómetros cuadrados o lo que resulte dentro de los siguientes linderos: al norte las Piedras Grandes y el borde de casa de piedra, por el sud el Río del Rosado, por el este la punta de Las Lomas y por el oeste La Cumbre que da vista a El Tolar".

Los ejemplos mencionados son suficientes para mostrar la imprecisión y/o superposición de los límites del campo, así como la superficie del mismo. ${ }^{12}$

Ahora bien, usar en común no significa que cualquier individuo puede usufructuar la tierra. Según los relatos de los habitantes de Asampay, para tener derechos de uso es indispensable ser heredero de un "dueño", y mejor aún tener "papeles"

12 Para un análisis más detallado ver Zubrzycki (2002). (escrituras, boletos de compraventa o hijuelas a nombre de un antecesor) y pagar los "territoriales", es decir, impuestos sobre la tierra que se abonan anualmente y que en todos los casos se encuentran a nombre de personas ya fallecidas, pero cuyos herederos en conjunto continúan pagando. ${ }^{13}$

“... nosotros somos dueños por parte de mi papá, somos herederos, mi hermano y yo hemos heredado la parte de mi papá. Nosotros pagamos todos los territoriales, los papeles, lo que ha sido de papá, esto está al día todo. Tenemos un documento de él, el título, así no más, porque aquí el que era dueño quedan dueños los hijos".

Respecto a la compra y venta de tierras, hace décadas que no se realiza ninguna, básicamente por la escasez de agua. Los pobladores se refieren a estas transacciones como "ventas bajo cerco", ya que lo que se vende es "la mejora", es decir, una casa o un rastrojo con agua. Ya nadie compra o vende sólo "derechos de campo" o "derechos de potrero".

Un tipo de transacción que sí se ha realizado algunas veces en las últimas décadas es la donación bajo cerco: “... nadie vende, porque ¿sabe qué? va teniendo familia, a los hijos les va dando una parte de tierra, de agua... lo que sí es que el agua no alcanza", "... eso es feo para vender así una propiedad y vender con agua, no nos conviene a los dueños, si quedamos ya sin agua. Por ejemplo, si yo tengo dos días de agua y quiero vender un pedazo de terreno voy a vender un día y me voy a quedar con un día de agua y no me conviene".

"Hay familias que tienen derechos de campo. Hay una gente que tiene muy poco derecho, que únicamente compró un lote para hacer la casa. No tiene derecho de campo, tienen derecho de casa nada más (...) nosotros vendimos allá, una casa que está allá, dentro de nuestro terreno, y dimos escritura y todo, pero vendimos sin agua. Donde está la posta sanitaria lo donamos nosotros, pero dentro de nuestro rastrojo. Donde está la capilla la donó un tío mío, pero la donó porque él la casa la tenía ahí, la escuela lo mismo, pero no era cercado. Esto se llama donaciones bajo cerco, bajo cerco del propietario. Nuestra propiedad no se puede donar si no tiene el bajo cerco, por-

13 Una situación similar ha sido registrada para el valle central de Catamarca por Pizarro (2000). 
que no tiene la misma seguridad. Por ejemplo si yo le doy a un hijo mío, yo tengo que darle una especie de minuta para la seguridad de él, sino no se llama donación, todas las donaciones que son, son bajo cerco".

La tenencia de las tierras es entonces legitimada por un lado a través de la relación genealógica con un "dueño", y por otro, por la posesión de algún documento que acredite tener derechos y el pago de impuestos territoriales.

“... es el mismo título, cada uno tiene todo lo mismo, las mismas dimensiones que tiene uno tiene el otro, porque esto ha sido derecho de campo... acción y derecho. Aquí nosotros tenemos derechos por nuestro padre, mis hermanos y yo pagamos el derecho todos los años, yo estoy pagando entre todos, hay una sola escritura porque aquí ni hay juicio sucesorio para tener título propio. Aquí el campo es comunero pero para los dueños de aquí, claro, si para eso estamos pagando los derechos. Por ejemplo de allá de Belén han sacado la leña, habían robado, vienen de noche y se meten ... no tienen que meterse, de la loma para arriba no tienen que meterse. Por ejemplo familiares que están en Belén de aquí, de alguno, sí, porque tiene los derechos. Otros no, ya tienen que pedir, hablar aquí con los dueños".

"El campo es en común ya... los que vivimos acá ¿no?, derecho para leña, así... Como hay mucha gente que está en Belén, que ha sido de aquí y se han ido a vivir a Belén, tienen también derechos para venir, hacer casa...".

En algunos casos, nietos y bisnietos de dueños originales que han dejado de pagar los impuestos y no tienen los papeles consideran que ya no tienen derecho de campo, pero sí tienen derechos sobre las casas y las parcelas cercadas por cada grupo doméstico. En estos casos, si las familias tienen hacienda, utilizan el campo solicitando "permiso" de uso a un pariente o vecino.

“... a mi mamá no le han entregado nada, a ninguna de las hermanas, ya una sola se ha quedado con las escrituras, la que quedó en la casa del abuelo, y bueno, después... Pero eso nadie sabe qué es lo que se han hecho, nada... digamos la gente que hemos quedado ¿no? los nietos de ellos que hemos quedado, nadie sabe qué es lo que ha pasado con la escritura... prácticamente no hay, estamos nosotros también, nada más amparando nuestra parte de la casa, lo que tenemos cercado. No podemos decir que tenemos por el campo derechos porque no lo sabemos, por más que digamos que ellos han sabido pagar, pero en vida de ellos han sabido pagar, han sabido tener todo el derecho que tenían, pero ahora nosotros ya no, solamente lo que tenemos bajo cerco. Y eso es lo único que amparamos nosotros, y bueno, del campo ya igual... tenemos la hacienda esa que está por el cerro, cerro común que le dicen ... don Cacho, él paga los derechos y él nos da, nos dice que nosotros podemos tener por ahí, tenemos derecho por parte de él, él nos da permiso para que tengamos los animales, los cabritos por el cerro".

Sin embargo, aunque en el discurso aparece la diferencia entre los dueños (herederos que tienen los papeles y pagan los territoriales), y los que no tienen derechos de campo común (no tienen papeles ni pagan impuestos), en la vida diaria sí hay un aprovechamiento comunal de los recursos del campo; los pastos y la leña son utilizados por todos los habitantes del pueblo, y éstos son parientes entre sí, todos, de alguna manera, herederos de un dueño. ${ }^{14}$ En última instancia son las relaciones de parentesco las que cuentan; en la práctica se pueden hacer pastar los animales en el campo por el sólo hecho de ser descendiente de un dueño. Se es dueño por ser heredero de un dueño; se es heredero por ser hijo, nieto o bisnieto de un dueño.

Las pasturas del monte sólo permiten la cría, fundamentalmente, de cabras y ovejas; en la actualidad, como ya señalamos, los rebaños son de pocos animales y sólo se los utiliza para el consumo, no para la comercialización, con lo cual no se genera "competencia" por los pastos. Décadas atrás, cuando una de las actividades económicas más importantes de la población, además del teji-

\footnotetext{
14 Toda la población de Asampay junto a la de algunos puestos vecinos está vinculada genealógicamente. Para más detalles ver Zubrzycki y Maffia (1999).

15 No nos detendremos a analizar las causas de la caída de la venta de cueros y la consecuente caída de la actividad ganadera. Sí podemos decir que para mediados del siglo XX cada vez es menor la rentabilidad de la cría de ganado menor; al mismo tiempo se hace frecuente la migración estacional masculina a la zafra tucumana y salteña (Maffia y Zubrzycki 2001).
} 
do en telar, era la venta de cueros ${ }^{15}$, el tener "derechos y acciones" o "derechos de estancia" sobre el campo tenía un significado mayor.

Lo que queda fuera de toda duda es la tierra "amparada", es decir, las parcelas con la casa, la huerta y los rastrojos cultivados, la cual es considerada de propiedad privada del grupo familiar que la detenta, conserve o no papeles, pague o no el territorial.

Otro tema de carácter privado es el agua, la que ha sido comprada y heredada por cada familia, aunque no hay un documento que reglamente su uso colectivo ni un mantenimiento comunal de las acequias y tomas de agua, trabajo que es realizado por empleados de la municipalidad. Cuando un poblador tiene problemas para regar gestiona en forma personal con algún vecino el préstamo de horas de agua.

Las obras para instalar el sistema de agua corriente fueron llevadas a cabo por la Municipalidad durante 1998, no por los asampeños, más allá de haber tramitado los vecinos en forma conjunta su realización. Este sistema de turnos acordados entre las mismas personas y no a través del arbitrio del Estado, no encuentra cabida en la legislación argentina.

\section{Conclusiones}

Hasta aquí expusimos en forma sintética cómo es la tenencia de la tierra en el campo comunero que estudiamos en el valle de Hualfín, comparando la situación con formas de tenencia comunal en poblaciones indígenas de la región andina (Bolivia, Perú y Noroeste Argentino).

En cierta manera, los pobladores de Asampay hacen uso de las tierras de la misma forma que en los casos descritos para las poblaciones indígenas del Noroeste Argentino: propiedad privada de las parcelas de cultivo y uso común de las tierras de pastoreo.

Sin embargo, en Asampay no existe la comunidad como modo de producción y distribución (Isla 1992), no hay apropiación, reparto y uso comunal de la tierra de labranza, ni una organización (junta vecinal, asociación civil, etc.) que regule el acceso a la misma; los pobladores ni siquiera se refieren a sí mismos como comuneros, sino como "dueños" o poseedores de "derechos de campo" (Zubrzycki 2003).

Si bien los habitantes más viejos marcan la diferencia entre los que tienen y los que no tienen derechos, en la práctica todos usan el campo, aunque algunas familias ya no paguen impuestos ni tengan papeles. Es la relación genealógica la que los "habilita" a continuar usufructuando el monte.

El caso de Asampay no responde al modelo de propiedad del sistema de Código Civil que cubrió el arco de 1871 a 1994. Pero tampoco podemos decir que se han recobrado modelos de gestión propios de comunidades indígenas andinas.

Es aceptable pensar que la gestión compartida que de los campos comuneros realizan los lugareños tiene alguna inspiración con la concepción vinculada al Período Hispánico -donde los pastos, bosques y aguas eran considerados comunes ${ }^{16}$ situación que, posiblemente por el relativo aislamiento de la comunidad, una economía fundamentalmente ganadera y ante la falta de resolución del tema de la indivisión de las tierras, nunca se terminó de adaptar al sistema impuesto por el Código Civil.

El análisis se refirió al campo comunero Asampay, pero lo que allí sucede no es exclusivo de esa zona. La misma situación se registra en otras áreas de Catamarca, en Tucumán, La Rioja, San Juan y Mendoza ${ }^{17}$, donde aún persisten indivisas grandes extensiones de tierras dedicadas al pastoreo, siendo sus pobladores comuneros por el uso en común de los pastos, no por la existencia de la comunidad.

Con los datos hasta aquí aportados será comprensible avizorar un dificultoso encuadre de la reali-

16 Assadourian cita un documento colonial recopilado en el Archivo de la Provincia de Córdoba que ejemplifica lo dicho: “... los vecinos de esta ciudad que se allan con asienda en la campaña de yeguas, mulas y bacas an gosado de todas las campañas, montes, pastos y aguadas, sin que se les aya impedido por ninguna persona por ser comunes..." AJC, legajo 179, f. 127 (Assadourian 1983: 39).

17 Díaz (1999), Doro (1974), Doro y Trinchero (1992), Olivera (1993), Pizarro (2000). 
dad de Asampay respecto de la normativa establecida en el Código Civil Argentino, en lo que al régimen de la tierra se refiere. ${ }^{18}$

Lo cierto es que por su relativo aislamiento, la poca rentabilidad de la tierra y, lo más importante, la escasez de agua, en el campo comunero estudiado no se ha generado un mercado de tierras ni re- valorización de la misma, como si sucedió por procesos de expansión de la frontera agropecuaria en otras zonas del Noroeste Argentino.

Esta situación, sumada a la mencionada relación genealógica que tienen todos los pobladores, ha permitido que no surjan importantes conflictos en el uso de la tierra. ${ }^{19}$

\section{REFERENCIAS CITADAS}

ASSADOURIAN, C. S., 1983. El sistema de la economía colonial. El mercado interior. Regiones y espacio económico. Nueva Imagen, México D. F.

BOCCO DE ABEYA, A., 1988. Contribución al conocimiento del espacio social pastoral de subsistencia. Estudio de caso: Los puesteros transhumantes del departamento de Malargüe. Mendoza. Cuadernos de Antropología Social (1) $1: 79-95$

CALVO, L. M. y P. REGALSKY, 1994. Sociedad étnica, territorio, unidad familiar y sistema productivo. En Raqaypampa. Los complejos caminos de una comunidad andina, P. Regalsky (Ed.), pp.13-48. Centro de Comunicación y Desarrollo Andino, Cochabamba.

CONSEJO FEDERAL DE INVERSIONES (CFI), 1964. Estudio sobre las mercedes de Los Llanos de La Rioja. Buenos Aires.

DIAZ, M., 1999. Tenencia de la tierra y uso del agua: ¿Factores de la desertificación? En Actas (electrónicas) de las Primeras Jornadas de Estudios Agrarios y Agroindustriales, Buenos Aires.

DORO, R., 1974. Diagnóstico expeditivo de la situación jurídica, económica y social de las áreas en situación de

18 Podríamos decir que las ventas efectuadas en las escrituras analizadas constituyen la transmisión de partes indivisas de un mismo inmueble. Ello nos habilitaría a pensar que estamos en presencia de condominios sujetos a la normativa de este derecho real. Pero más allá de pensar que estas disposiciones resultan de difícil aplicación práctica, los datos hasta el momento colectados no nos permiten asegurar tal encuadre. Otra posible interpretación de los negocios jurídicos efectuados los ubicaría en el lugar de sucesivas cesiones de derechos hereditarios, mayormente en los casos en los que las sucesiones de los ascendientes no fueron tramitadas. Pero cabe destacar que las transmisiones efectuadas no tienen por objeto derechos reales, sino personales. Ello equivale a decir que lo que se transmite no es la propiedad de la tierra, sino todo el conjunto de derechos y acciones que por su situación de herederos le pudieran corresponder. Para un análisis más profundo ver Maffia y colaboradores (1999) y Pastorino y colaboradores (2000 y 2001). comunidades indivisas de la provincia de Tucumán. Consejo Federal de Inversiones, Buenos Aires.

DORO, R. y H. TRINCHERO, 1992. La propiedad del suelo: Algunas precisiones conceptuales y su análisis en el espacio rural argentino. En Antropología Económica II. Conceptos fundamentales, $\mathrm{H}$. Trinchero (Comp.), pp. 167-185. CEAL, Buenos Aires.

ESPECHE, F., 1875. La Provincia de Catamarca. Imprenta Biedma, Buenos Aires.

GONZALEZ, A. R., 1955. Contextos culturales y cronología relativa en el área Central del NO Argentino. Anales de Arqueología y Etnología 12.

GONZALEZ, A. R. y G. COWGILL, 1975. Cronología del valle del Hualfín. En Actas y trabajos del Primer Congreso Nacional de Arqueología Argentina, pp. 243-283, Rosario.

HOCSMAN, L. D., 1999. Economía doméstica agropastoril, propiedad y uso del espacio en la cordillera oriental (Salta). En Actas de la III Reunión de Antropología del Mercosur, Misiones.

- 2000. Transhumancia y sistema de uso común del territorio en la cordillera oriental (Salta). En Actas de las IV Jornadas Rosarinas de Antropología Social, Rosario.

ISLA, A., 1992. Dos regiones, un origen. Entre el "silencio" y la furia. En Sociedad y articulación en las tierras altas jujeñas. Crisis terminal de un modelo de desarrollo, A. Isla (Ed.), pp. 167-215. ECIRA - ASAL - MLA, Buenos Aires.

-2002. Los usos políticos de la identidad. Indigenismo y Estado. Editorial de las Ciencias, Buenos Aires.

LARROUY, A., 1921. Catamarca Colonial. Formación y colonización de la Provincia. Autonomía Catamarqueña, Catamarca.

19 Hemos detectado algunas disputas y rivalidades entre los grupos familiares por el tema de la herencia del agua y de la tierra cercada, es decir, las parcelas de propiedad "privada", pero el tema excede el presente trabajo. 
MADRAZO, G., 1970. Contribución para el estudio histórico de la tenencia colectiva de tierras en la provincia de Jujuy. Relaciones 5 (1): 57-67.

MAFFIA, M., L. PASTORINO, B. ZUBRZYCKI y M. DE LUCA, 1999. La propiedad de la tierra y el agua en la localidad de Asampay, provincia de Catamarca. Una visión desde la antropología sociocultural y el derecho. En Actas de las Primeras Jornadas de Estudios Agrarios y Agroindustriales, Buenos Aires.

MAFFIA, M. y B. ZUBRZYCKI, 2001. Migraciones en Catamarca: El caso de la pequeña localidad de Asampay. Estudios Migratorios Latinoamericanos 47: 149-179.

OLIVERA, G., 1993. El campo comunero de Isla Verde. Transición desde el régimen comunal al privado de la tierra (La Rioja, siglos XIX y XX). Ruralia 4: 61-78.

OSSIO ACUÑA, J., 1992. Parentesco, reciprocidad y jerarquía en los Andes. Una aproximación a la organización social de la comunidad de Andamarca. Fondo Editorial, Pontificia Universidad Católica del Perú, Lima.

PASTORINO, L., M. DE LUCA, B. ZUBRZYCKI y M. MAFFIA, 2000. La articulación entre la normativa legal vigente y la tradición consuetudinaria en relación con la tierra y el agua en el departamento de Belén, provincia de Catamarca. En Actas de las Segundas Jornadas Platenses de Geografía, La Plata.

PASTORINO, L., M. DE LUCA, M. MAFFIA y B. ZUBRZYCKI, 2001. Campos indivisos y comuneros en Asampay (Belén-Catamarca). Impacto del Derecho positivo (monismo jurídico) en el desarrollo regional y agroecológico. En Actas de las II Jornadas Interdiscipli- narias de Estudios Agrarios y Agroindustriales, Buenos Aires.

PIZARRO, C., 2000. La política cultural de las movilizaciones campesinas en Catamarca. CENEDIT, Universidad Nacional de Catamarca, Catamarca.

SANCHEZ LOPEZ, F., 1998. Modelos de gestión de sistemas de recursos comunales en Castilla y León. Consejería de Economía y Hacienda, Junta de Castilla y León, Ponferrada.

SEMPE, C., 1976. Contribución a la arqueología del Valle de Abaucán, departamento Tinogasta, Catamarca. Tesis Doctoral, Facultad de Ciencias Naturales y Museo, Universidad Nacional de La Plata, La Plata.

WEISER, V., 1926 Ms. Diarios de campo de las expediciones realizadas al noroeste argentino entre 1920 y 1926. Departamento Científico de Arqueología, Facultad de Ciencias Naturales y Museo, Universidad Nacional de La Plata, La Plata.

ZUBRZYCKI, B. y M. MAFFIA, 1999. Parentesco y organización familiar en una comunidad rural del valle de Hualfín, Catamarca. En Actas electrónicas de la III Reunión de Antropología del Mercosur, Misiones. (CDROM, ISBN 987-9136-96-9).

ZUBRZYCKI, B., 2002. Campos comuneros en el valle de Hualfín (Catamarca). Antecedentes, problemática y situación actual. Andes. Antropología e Historia 13: 305-320.

2003. Herederos, dueños y "derechosos". Propiedad y herencia de la tierra en el campo comunero Asampay, Argentina. Sociedades Rurales, Producción y Medio Ambiente 4 (1): 19-27. 